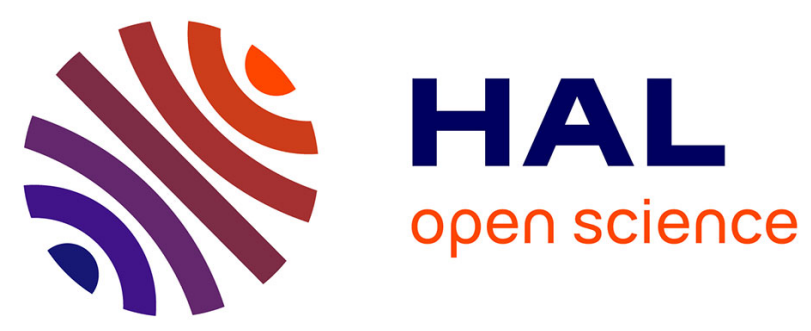

\title{
FerrateVI oxidation of polycyclic aromatic compounds (PAHs and polar PACs) on DNAPL-spiked sand: degradation efficiency and oxygenated by-product formation compared to conventional oxidants
} Clotilde Johansson, Philippe Bataillard, Coralie Biache, Catherine Lorgeoux, Stéfan Colombano, Antoine Joubert, Thierry Pigot, Pierre Faure

\section{To cite this version:}

Clotilde Johansson, Philippe Bataillard, Coralie Biache, Catherine Lorgeoux, Stéfan Colombano, et al. FerrateVI oxidation of polycyclic aromatic compounds (PAHs and polar PACs) on DNAPL-spiked sand: degradation efficiency and oxygenated by-product formation compared to conventional oxidants. Environmental Science and Pollution Research, 2019, 27 (1), pp.704-716. 10.1007/s11356-019-068410 . hal-02429233

\section{HAL Id: hal-02429233 https://hal.science/hal-02429233}

Submitted on 10 Dec 2020

HAL is a multi-disciplinary open access archive for the deposit and dissemination of scientific research documents, whether they are published or not. The documents may come from teaching and research institutions in France or abroad, or from public or private research centers.
L'archive ouverte pluridisciplinaire HAL, est destinée au dépôt et à la diffusion de documents scientifiques de niveau recherche, publiés ou non, émanant des établissements d'enseignement et de recherche français ou étrangers, des laboratoires publics ou privés. 


\title{
Ferrate $^{\mathrm{VI}}$ oxidation of Polycyclic Aromatic Compounds (PAHs and polar PACs) on DNAPL-spiked sand: degradation efficiency and oxygenated by-product formation compared to conventional oxidants
}

\author{
Clotilde Johansson ${ }^{\mathrm{a}, \mathrm{b}, \mathrm{c}, \mathrm{d}}$, Philippe Bataillard ${ }^{\mathrm{b}}$, Coralie Biache ${ }^{\mathrm{a}}$, Catherine Lorgeoux ${ }^{\mathrm{c}}$, Stéfan
} Colombano $^{\mathrm{b}}$, Antoine Joubert ${ }^{\mathrm{d}}$, Thierry Pigot ${ }^{\mathrm{e}}$ and Pierre Faure ${ }^{\mathrm{a},{ }^{*}}$

\author{
${ }^{a}$ Université de Lorraine, CNRS, Laboratoire Interdisciplinaire des Environnements Continentaux \\ (LIEC), Vandœuvre-lès-Nancy, 54506, France \\ ${ }^{b}$ Bureau de Recherches Géologiques et Minières (BRGM), 45060 Orléans, France \\ ${ }^{c}$ Université de Lorraine, CNRS, CREGU, GeoRessources, Vandouvre-lès-Nancy, 54506, France \\ ${ }^{d}$ SERPOL, 2 chemin du Génie, BP 80, Vénissieux, 69633, France \\ ${ }^{e}$ Université de Pau \& Pays Adour, CNRS, Institut des Sciences Analytiques et de Physico-Chimie pour \\ l'Environnement et les Matériaux (IPREM UMR CNRS 5254), Pau, 64000, France \\ *Corresponding author: pierre.faure@univ-lorraine.fr
}

\begin{abstract}
In-situ Chemical Oxidations are known to remediate PAH contaminations in groundwater and soils. In this study, batch scale oxidations aim to compare the PAC (polycyclic aromatic compound) degradation of three oxidation processes traditionally applied for soil treatment: permanganate, heat activated persulfate $\left(60^{\circ} \mathrm{C}\right)$ and Fenton-like activated by magnetite, to results obtained with ferrates $\left(\mathrm{Fe}^{\mathrm{VI}}\right)$. Widely studied for water treatments, ferrates are efficient on a wide range of pollutants with the advantage of producing non-toxic ferric sludge after reaction. However, fewer works focuses on their action on soil, especially on semi-industrial grade ferrates (compatible with field application).

Oxidations were carried out on sand spiked with dense non aqueous phase liquid (DNAPL) sampled in the groundwater of a former coking plant. Conventional 16 US-EPA PAHs and polar PACs were monitored, especially potential oxygenated by-products that can be more harmful than parent-PAHs. After seven reaction days, only the Fenton-like showed limited degradation. Highest efficiencies were obtained for heat-activated persulfate with no O-PAC ketones formed. Permanganate gave important degradation, but ketones were generated in large amount. The tested ferrates gave slightly lower yields due to their auto-decomposition but also induced O-PAC ketone production, suggesting a reactional pathway dominated by oxido-reductive electron transfer, rather than a radical one.
\end{abstract}

\section{Keywords:}

Soil and groundwater remediation

O-PAC ketones

Fenton-like

Potassium permanganate

Activated persulfate

DNAPL

\section{Acknowledgement}

This work was supported by the French Environmental Agency (ADEME) and the French National Association for Research and Technology (ANRT). The funding sources had no other involvement in this study. We thank ARCELORMITTAL FRANCE for the assistance provided in the BIOXYVAL project, particularly for the provision of a site that allowed proper execution of the project's work. We also thank the GISFI (French Scientific Interest Group - Industrial Wasteland) for materials and Mr G. Bessaque from GeoRessources for his help in designing/constructing useful equipments. Dr Mustapha 
Abdelmoula from LCPME- UMR 7564 is acknowledged for performing the Mössbauer experiments and his expertise in Mössbauer spectroscopy, and both Jérôme Frayret from IPREM, UMR

CNRS/UPPA 5254 and Jan Slunski from NanoIron are thanked for providing the ferrate powders and for their help in understanding the behavior of this oxidant.

The anonymous reviewers are thanked for their constructive comments to improve the paper's quality.

\section{Highlights:}

- $\mathrm{KMnO}_{4}$, activated $\mathrm{Na}_{2} \mathrm{~S}_{2} \mathrm{O}_{8}$, Fenton-like and ferrate ${ }^{\mathrm{VI}}$ were used for DNAPL degradation

- Activated $\mathrm{Na}_{2} \mathrm{~S}_{2} \mathrm{O}_{8}$ gave higher degradation, generated no O-PACs but lowered the $\mathrm{pH}$

- $\mathrm{KMnO}_{4}$ gave very good abatement, except for O-PAC furans, and formed many ketones

- Despite auto-degradation, Ferrates showed good efficiency, but generated ketones

\section{Introduction}

The coke used in steelwork industry is obtained by coal purification through the coking process, which generates coal-tar as by-product. Coal-tar corresponds to a mixture of thousands of Polycyclic Aromatic Compounds (PACs) including Polycyclic Aromatic Hydrocarbons (PAHs) and polar-PACs containing one or more heteroatoms (oxygen, nitrogen or sulphur) (Benhabib et al., 2010; Birak and Miller, 2009; Tian et al., 2017; Wehrer et al., 2011). PAHs are well known for their toxicity, carcinogenicity, mutagenicity and reproductive toxicity (Marin-Morales, MA; Leme, DM; Mazzeo, 2009; Mumtaz and George, 1995). Due to their high hydrophobicity, PAHs are preferably adsorbed on natural organic matter or mineral phases present in soil, what contributes to their persistence (Bandowe and Wilcke, 2010; Delle Site, 2001).

Sixteen representative PAHs are targeted by the US Environmental Protection Agency as priority pollutants, while no polar-PACs are regulated, despite their proven toxicity - sometimes even higher than PAHs - towards a wide variety of organisms (Lübcke-von Varel et al., 2011; Lundstedt et al., 2007b; Zamfirescu and Grathwohl, 2001). With higher polarities, these compounds have a higher solubility into water, and consequently a better mobility in soil than parent compounds (Biache et al., 2011; Hanser et al., 2014; Lundstedt et al., 2007b).

Accidental spills of coal-tars, or former waste management practices, have contributed to soil and groundwater pollution at many industrial sites. Due to environmental- and health-risks, decontamination of these wastelands is of great concern. In Situ Chemical Oxidation (ISCO) represents a group of reactions able to break down PACs directly in the soil or groundwater.

Ideally, the oxidation is complete, and PACs are mineralized into $\mathrm{CO}_{2}$ and water. When the oxidant dose is insufficient, the reaction may generate some harmful oxygenated PACs (ketones) (Biache et al., 2011; Guan et al., 2014; Lampi et al., 2006; Lundstedt et al., 2007b; Peings et al., 2015; Ranc et al., 2017; Russo et al., 2010).

Several oxidants, such as permanganate, activated persulfate or iron II catalysed hydrogen peroxide, named Fenton or Fenton-like processes, have been well studied and are commonly used for soil remediation (Huling and Pivetz, 2006; ITRC, 2005; Ranc et al., 2016). Permanganate is an oxidant 
reacting with oxido-reductive pathway (two electron transfers) known to persist (weeks to months) in soils and aquifers (de Souza e Silva et al., 2009; Huling and Pivetz, 2006; Ranc et al., 2017). It shows a long-lasting efficiency, but generates $\mathrm{MnO}_{2}$ precipitates which can alter soil permeability and can inhibit regrowth of vegetation (Sirguey et al., 2008) and can alter or change micro-organisms diversity (Liao et al., 2019). Very effective to degrade PAHs (Boulangé et al., 2019b; Lemaire et al., 2019; Liao et al., 2019, 2018; Ranc et al., 2017), its efficiency on PACs is dependent on molecular size and aromatic condensation structure (Clar and Schoental, 1964; Forsey et al., 2010; Wang et al., 2015). Catalyzed Hydrogen peroxide in Fenton reactions forms the hydroxyl-radical $(\mathrm{HO} \bullet)$, a highly reactive radical with a short lifespan, which degrades organic matter without selectivity (Ferrarese et al., 2008; Rivas, 2006; Watts et al., 2002). This reaction is catalysed by iron II in solution at low pH (2-5) (Gallard et al., 1998; Kwan and Voelker, 2002). Fenton-like reactions can also be conducted under circumneutral pH, more compatible with soils, with heterogeneous catalytic systems where the iron is present in a mineral phase such as magnetite (Biache et al., 2015; Boulangé et al., 2019b; Jung et al., 2009; Munoz et al., 2015; Usman et al., 2012a; Voinov et al., 2011). The efficiencies of all Fenton type reactions to degrade PAH (Cheng et al., 2016; Trellu et al., 2016), especially in contaminated soils are widely discussed in the literature (Usman et al., 2016; Venny et al., 2012; Yap et al., 2011). Persulfate can be activated by heat, metallic catalysts, high or low $\mathrm{pH}$, hydrogen peroxide $\left(\mathrm{H}_{2} \mathrm{O}_{2}\right)$, or UV-light to generate sulfate radicalanion $\left(\mathrm{SO}_{4} \bullet-\right)$, almost as reactive as the hydroxyl radical. Depending on the catalyst used and how the contact with the oxidant is efficient, hydrogen peroxide and persulfate may persist in soils and release radicals over longer time periods, compared to the short radical lifespan. Persistence in soils is usually higher for persulfate (weeks), than hydrogen peroxide (minutes to hours) as persulfate is more stable in sub-surface (Huang et al., 2002). Activated persulfate have shown high efficiency for PAHs degradation (Cassidy et al., 2015; Chen et al., 2015; Kakosová et al., 2017; Lemaire et al., 2019; Liao et al., 2019, 2018; Peng et al., 2016; Ranc et al., 2017; Song et al., 2019). Sulfate radical-anion shows selectivity towards low molecular mass compounds (Gryzenia et al., 2009; Usman et al., 2012a). Its main drawback is the formation of sulfates and sulfuric acid as oxidation end-products, inducing a drastic $\mathrm{pH}$ decrease.

Recently, the use of ferrates VI as a water treatment to oxidize organic pollutants (laboratory experiments) has been well documented. This strong oxidant reacts on a wide range of agents as pharmaceuticals, pesticides, phenols, cyanide, heavy metals, microorganisms, natural organic matter (Bielski et al., 1994; Filip et al., 2011; Gan et al., 2015; Hrabak et al., 2016; Jiang et al., 2006; Johnson and Sharma, 1999; Liu et al., 2019; Manoli et al., 2019; Peings et al., 2017, 2015; Rai et al., 2018; Sharma, 2013, 2008; Yngard et al., 2008), and aromatic structures like BTEX (Lacina and Goold 2015; Minetti et al. 2017), water lixiviates from bitumen (Wang et al., 2016) and PAHs (Guan et al., 2014). It releases $\mathrm{O}_{2}, \mathrm{HO}^{-}$and ends as $\mathrm{Fe}(\mathrm{OH})_{3}$, which has flocculent properties and is nontoxic towards the environment. This oxidant can follow two reaction pathways: free radicals with one electron transfer and oxidoreductive with two electrons exchange, often via oxygen atom transfer, supported by the reactions: 
$\mathrm{Fe}^{\mathrm{VI}}+\mathrm{R}$ (organic compound) $\rightarrow \mathrm{Fe}^{\mathrm{V}} / \mathrm{Fe}^{\mathrm{IV}}+\mathrm{RO} / \mathrm{R}^{\bullet} \rightarrow \mathrm{Fe}^{\mathrm{III}} / \mathrm{Fe}^{\mathrm{II}}$-hydroxides $+\mathrm{R}^{\prime}$ (organic by-products) $\mathrm{Fe}^{\mathrm{VI}}$ can also react with an induced radical $\mathrm{R} \cdot$ to form $\mathrm{Fe}^{\mathrm{V}}$ and $\mathrm{RO}$ species (Sharma, 2013). Therefore, reactions on PAHs are expected to form O-PACs, which has been attested by Guan et al., (2014).

Ferrate also shows selectivity towards nucleophilic sites (Sharma, 2013). Peings et al. (2015) have applied this oxidant on a real wastewater mixture containing numerous organic pollutants. They have shown that the organic bulk enters in competition with pollutants towards oxidation, but the degradation remains selective: with enough oxidant, nearly all contaminants are degraded whereas the dissolved organic carbon is less affected.

To our knowledge, among the published studies presenting the ferrate's oxidation potential, only few deal with the oxidation of PAHs on soil (or solid matrix) and subsequent formation of polar-PACs by ferrates (Guan et al., 2014), and none concern ISCO treatment to degrade a real wasteland Dense Non Aqueous Phase Liquids (DNAPL).

This study is linked to the BIOXYVAL project, aimed to propose adapted treatment solutions for sites highly impacted by organics, especially connected to a workshop site, former coking plant, contaminated by DNAPL. As a matter of fact, all the oxidants compared in this study were selected to be compatible with field application.

Therefore, the aim of this contribution is to investigate the efficiency of two potassium ferrate (of semi-industrial grade) to degrade DNAPL on a solid matrix, compared with conventional oxidants for soil treatment: potassium permanganate, heat activated persulfate and Fenton-like (magnetite-activated). Sand spiked with DNAPL (sampled on the coking plant wasteland) was immerse in deionized (DI) water to mimic an ideal groundwater-like system. The 16 US EPA PAHs and some polar-PACs, either present in the initial coal-tar or identified as potential by-products (12 O-PACs, 5 N-PACs and 4 S-PACs), were targeted.

\section{Materials and methods}

\section{$2.1 \quad$ Chemicals}

For analysis and organic extraction, dichloromethane DCM (Biosolve), methanol (Carlo Erba), acetone (Biosolve), and hexane (Biosolve) of HPLC grade were used.

Sodium azide $\left(\mathrm{NaN}_{3}, 99.0 \%\right.$ Sigma Aldrich) was used as biocide $(200 \mathrm{mg} / \mathrm{L})$.

Deionized (DI) water was produced with a Pure-Lab Option system from Elga.

\subsection{Matrices}

\subsubsection{Dense Non Aqueous Phase Liquid (DNAPL)}


DNAPL was sampled in summer 2016 at 3-4 $\mathrm{m}$ deep by pumping it from a pool present in groundwater layer at a former coking plant (Lorraine, -France). The coking plant was in operation from 1912 to 1973.

The DNAPL was first separated from its aqueous phase by decantation, then filtered on glass microfiber filters (GF/D-Whatman).

In order to limit further loss of compounds by evaporation and the subsequent overestimation of the degradation efficiency, DNAPL was previously treated on a Rotovap R-215 BUCHI to remove the most volatile compounds. Additionaly, bentonite ( $4 \mathrm{~g}$ ) was added to the batch before freezing and drying the samples, for its ability to retain Low Molecular Weight (LMW) PAHs (Lee et al., 2012). Its elevated specific area $\left(55-75 \mathrm{~m}^{2} / \mathrm{g}\right)$ limited pollutant evaporation but did not impact the extraction step. These pretreatments decreased losses of quantified molecules by evaporation to an average of $10 \%$, same order of magnitude than the uncertainty of our mesures.

For the sand spiking, this DNAPL was diluted in dichloromethane at $17 \mathrm{~g} / \mathrm{L}$ and kept in a brownglass flask at $4{ }^{\circ} \mathrm{C}$.

Elementary analysis $(\mathrm{C}, \mathrm{H}, \mathrm{O}, \mathrm{N}, \mathrm{S})$ was done by the laboratory of Physical Measurements of Montpellier University-France, by catalytic combustion in an Elementar Vario Micro Cube.

\subsubsection{Solid matrices}

Fontainebleau sand (180-500 $\mu \mathrm{m}$, Carlo Erba Reagents) was previously cleaned by accelerated solvent extractor (Dionex ASE 350), with DCM/methanol (50/50 v/v) at $130{ }^{\circ} \mathrm{C}$ and $100 \mathrm{bars}$, with a static time of $2 \mathrm{~min}$.

Bentonite from Georgia was cleaned twice with a DCM/methanol $(50 / 50 \mathrm{v} / \mathrm{v})$ mixture agitated under softly warming at $35-40{ }^{\circ} \mathrm{C}$, and then dried under nitrogen flux before use.

\subsection{Oxidants}

Four different oxidants were used:

- Potassium permanganate $\left(\mathrm{KMnO}_{4} 99+\%\right.$, Acros Organics),

- Hydrogen peroxide $\left(\mathrm{H}_{2} \mathrm{O}_{2} 30 \%\right.$, Analar Normapur VWR Chemicals), catalyzed by a Fenton-like process with magnetite $\left(\mathrm{Fe}_{3} \mathrm{O}_{4}-97 \%, 44 \mu \mathrm{m}\right.$, Alfa Aesar) at room temperature,

- Sodium persulfate $\left(\mathrm{Na}_{2} \mathrm{~S}_{2} \mathrm{O}_{8}, 95+\%\right.$, Fisher Scientific), heat activated at $60^{\circ} \mathrm{C}$.

- Ferrates: $\mathrm{K}_{2} \mathrm{FeO}_{4} 12 \%$ in form of millimetric pellets (named ferrate (1)) prepared from patented procedure FR2908128 (Castetbon et al., 2008) (France), and Envifer $\mathrm{K}_{2} \mathrm{FeO}_{4} 38.6 \%$ as pulverulent powder (named ferrate (2)) from Nano Iron (Czech Republic). Both are synthesized following less expensive processes, capable of producing semi-industrial-scale quantities (compared with ferrate of higher purity, not affordable for site application). These two semi-industrial ferrates are, to our knowledge, of the only ones currently available on the market, and therefore representative of potential products for field applications. The impurity of ferrate (1) was demonstrated to have no 
impact on its oxidative activity on phenols (Peings et al., 2015). PACs are expected to follow same trend.

\subsection{Batch oxidations}

Initial conditioning: sand $(4 \mathrm{~g})$ was spiked with $50 \mathrm{mg}$ DNAPL ( $2.94 \mathrm{~mL}$ of the $17 \mathrm{~g} / \mathrm{L}$ solution) in a $250 \mathrm{~mL}$ round-bottom glass flask. The mixtures were homogenized by agitation and the solvent was evaporated at room temperature overnight. DI water with $\mathrm{NaN}_{3}(50 \mathrm{~mL})$ was then added into the bottle (except for the persulfate as toxic gas could be emitted due to medium acidification). This sample corresponds to the starting point $\mathrm{t}_{0}$.

Oxidant dose: Oxidations were performed at one Stoichiometric Oxidant Demand (SOD), calculated from a Stoichiometric Molar Ratio (SMR) of the complex mixture of pollutants by measuring the Extractable Organic Matter (EOM) content and the elementary composition of the DNAPL, following the method proposed by Ranc et al (Ranc et al., 2016) (Supplementary Information 1.).

Oxidation procedure: The oxidants were poured as one single addition $\left(839 \mu \mathrm{L} \mathrm{H}_{2} \mathrm{O}_{2} 30 \%, 874 \mathrm{mg}\right.$ of $\mathrm{KMnO}_{4}, 2.037 \mathrm{~g}$ of persulfate and 9.0 and $2.8 \mathrm{~g}$ of ferrate (1) and (2), respectively) just before closing the bottle. For the Fenton-like reaction, a molar ratio $\mathrm{H}_{2} \mathrm{O}_{2} / \mathrm{Fe}$ of $10 / 1$ was chosen according to previous studies (Jung et al., 2009; Pera-Titus et al., 2004; Silva et al., 2009; Usman et al., 2012b). The magnetite was added to the bottle before the oxidant. $\mathrm{H}_{2} \mathrm{O}_{2}(30 \%)$ solution was then introduced drop by drop in the batch by pipetting it over one minute, to limit the oxidant's auto-degradation. Control samples were performed with DI water and biocide (without oxidant) at ambient temperature, and at $60^{\circ} \mathrm{C}$ as a reference for activated persulfate oxidation. The bottles were placed in darkness and magnetically stirred at room temperature for $3 \mathrm{~h}, 24 \mathrm{~h}$ and 7 days (triplicates). Initial $\mathrm{pH}$ was measured on the blanks. During the oxidation, bottles were hermetically closed to avoid loss of compounds by evaporation.

Oxidized sample processing: At the sampling time, the bottles were opened, and $\mathrm{pH}$ was measured (Hanna Instrument HI $255 \mathrm{pH} / \mathrm{mV}$ Combined Meter - HI 1131 electrode). At the end of the reaction time, bentonite $(4 \mathrm{~g})$ was added to the sample and stirred for 30 minutes before being freezed. For the $60^{\circ} \mathrm{C}$-experiments (persulfate), temperature was lowered by placing the flasks into cold water $\left(15^{\circ} \mathrm{C}\right)$ during 10 min before adding bentonite. The frozen samples were freeze-dried with a Cryotec freezedryer connected to an Edwards RV5-vacuum pump.

\subsection{Extractable Organic Matter (EOM) isolation (DNAPL)}

The EOM represents the fraction of organic matter that is recovered by adding DCM (40 $\mathrm{mL})$ to the sample and heated $\left(36^{\circ} \mathrm{C}\right)$ under stirring and reflux conditions for 30 minutes. The supernatant was then 
isolated by filtration through a glass-microfiber filter (GF/F- Whatman). The extraction was carried out twice. Solvent was then evaporated under $\mathrm{N}_{2}$ flux and the volume adjusted to $20 \mathrm{~mL}$. Aliquots $(3 \mathrm{~mL})$ were transferred in pre-weighed vials and the EOM contents were determined by weighing the vials after solvent evaporation at room temperature overnight. The remaining EOMs were kept in the dark at $4{ }^{\circ} \mathrm{C}$.

As the DNAPL is fully soluble in DCM, EOM is assumed to represent the whole pollution.

\subsection{Analytical methods}

\subsubsection{PAC quantification by Gas Chromatography-Mass Spectrometry}

Sixteen PAHs (US EPA PAHs), 12 O-PACs, 5 N-PACs and 4 S-PACs were quantified by Gas Chromatography coupled to a Mass Spectrometer (GC-MS) using internal deuterated standards (naphthalene D8, acenaphthene D10, phenanthrene D10, pyrene D10, chrysene D12, perylene D12, benzo(ghi)perylene, quinoline D7, 9H fluorenone D8). Two calibration curves were drawn for low (0, $0.06,0.12,0.18,0.3$ and $0.6 \mu \mathrm{g} / \mathrm{mL})$, and high concentrations $(0.18,0.3,0.6,1.2,3,6$ and $9.6 \mu \mathrm{g} / \mathrm{mL})$. The instrument used was a GC Agilent Technology 6890N equipped with a column DB-5MS (60 m $\times$ $0,25 \mathrm{~mm}$ d.i. $\times 0,25 \mu \mathrm{m}$ film thickness - Agilent Tech.) coupled to an Agilent 5973 inert Mass Selective Detector. One microliter of sample was injected at $300{ }^{\circ} \mathrm{C}$ in splitless mode. The GC oven temperature was programmed from $70{ }^{\circ} \mathrm{C}$ (held $2 \mathrm{~min}$ ) to $130^{\circ} \mathrm{C}$ at $15{ }^{\circ} \mathrm{C} / \mathrm{min}$, then from 130 to $315^{\circ} \mathrm{C}$ (held 30 $\min$ ) at $4{ }^{\circ} \mathrm{C} / \mathrm{min}$. The carrier gas was helium at $1.6 \mathrm{ml} / \mathrm{min}$ at constant flow.

Three analyses were carried out on each EOM sample: (i) quantitative analysis in Single Ion Monitoring (SIM) mode (Online Resources Table ESM_1), to lower the detection limit for all targeted molecules, (ii) qualitative analysis in Scan mode, and (iii) qualitative analysis (Scan mode) of the EOM previously derivatized (BSTFA-TMCS (99:1 Sylon BFT, Supelco)/sample (50/50 v/v) heated at $60{ }^{\circ} \mathrm{C}$ for $30 \mathrm{~min}$ (Wenclawiak et al., 1993)) to detect acids and alcohols.

\subsubsection{Infra-Red spectroscopy}

The recording was done on the EOM dried residue by light-transmission measurements with the instrument Bruker IFS 55 (resolution $2 \mathrm{~cm}^{-1}, 64$ scans/sample) coupled to a $250 \mathrm{~mm}$ narrow band MCT detector cooled to $77 \mathrm{~K}$. A small drop of the residue was placed on a diamond window ( $2 \mathrm{~mm}$ large, 1 $\mathrm{mm}$ thick). Selection of the analysed area was done with a visible light $\times 10$ objective. A restrictor was then placed to limit the beam width to $60 \mu \mathrm{m}$. Background was first done on an empty part of the diamond window and sample was measured afterwards.

Assignments of the main infrared bands were determined by reference to previous works (Bellamy, 1980; Landais and Rochdi, 1990).

\subsubsection{Mössbauer and ICP OES}


Ferrate (2) and its dry residue after seven days of reaction were analysed to characterize the iron speciation before and after oxidation. Mössbauer spectroscopy analyses were conducted at $300 \mathrm{~K}, 77 \mathrm{~K}$ and 14-15 K (Laboratoire de Chimie Physique et Microbiologie pour les Matériaux et l'Environnement LCPME - CNRS - University of Lorraine, France).

Iron was quantified in the ferrate modalities by ICP-OES (ICP 720 ES Varian) - (Laboratoire Interdisciplinaire des Environnements Continentaux LIEC - CNRS - University of Lorraine, France).

\section{Results}

\subsection{Initial samples \\ DNAPL characterization}

The molecular distribution of the DNAPL was mainly dominated by two and three-ring PACs (Online Resources Figure ESM_1). PAC quantification (Table 1) revealed the predominance of Acenaphthene, Fluorene and Phenanthrene (PAHs), Dibenzofuran (O-PAC), Dibenzothiophene (S-PAC), Quinoline and 9H-Carbazole (N-PACs). Compounds with more than three aromatic rings were observed in limited abundance (mainly Fluoranthene and Pyrene). Calculated from the individual PAC quantifications, the quantified molecules represent only $16.2 \mathrm{wt} \%$ of the total DNAPL mass, which attests a complex pollutant mixture.

The Fourier Transformed InfraRed spectroscopy (FTIR) analysis (Fig1a) depicts the type of chemical bonds present in the DNAPL. Aromaticity is clearly expressed with intense $\mathrm{vCH}_{\text {aro }}\left(3100-3000 \mathrm{~cm}^{-1}\right)$, $\nu \mathrm{C}=\mathrm{C}\left(1650-1550 \mathrm{~cm}^{-1}\right)$ and $\gamma \mathrm{CH}_{\text {aro }}$ bands $\left(900-700 \mathrm{~cm}^{-1}\right.$; with $1 \mathrm{H}$ centred on $875 \mathrm{~cm}^{-1}, 2-3 \mathrm{H}$ on 830 $\mathrm{cm}^{-1}$ and $4-5 \mathrm{H}$ centred on $\left.750 \mathrm{~cm}^{-1}\right)$. The $4-5 \mathrm{H}$ bands predominance in the $\gamma \mathrm{CH}_{\text {aro }}$ area attests the low condensation degree of the pollutants.

Aliphatic bands were also observed: $\mathrm{vCH}_{\mathrm{ali}}\left(3000-2800 \mathrm{~cm}^{-1}\right)$ and $\delta \mathrm{CH}_{\text {ali }}\left(1470-1440 \mathrm{~cm}^{-1}\right)$. They are suspected to mostly represent the ramifications on benzenic rings with short chain adducts (methyl, ethyl) as the intensity of $\mathrm{v}_{\mathrm{as}} \mathrm{CH}_{2}\left(2880 \mathrm{~cm}^{-1}\right)$ is lower than the $\mathrm{v}_{\mathrm{as}} \mathrm{CH}_{3}\left(2920 \mathrm{~cm}^{-1}\right)$.

Some heteroatom bands reveal the occurrence of nitrogen $\left(v \mathrm{C}-\mathrm{N}: 1220-1020 \mathrm{~cm}^{-1}\right.$ and $v \mathrm{~N}-\mathrm{H}: 3500-$ $\left.3050 \mathrm{~cm}^{-1}\right)$ and oxygen $\left(v \mathrm{C}=\mathrm{O}: 1750-1700 \mathrm{~cm}^{-1}\right.$ and $\left.v \mathrm{C}-\mathrm{O}: 1300-1170 \mathrm{~cm}^{-1}\right)$ functions.

The elemental composition (C: $84.1 \%, \mathrm{H}: 5.8 \%, \mathrm{~N}: 0.3 \%$, O: $5.3 \%$ and S: $4.1 \%$ in weight $\%$ ) of the DNAPL is typical of a dominated aromatic structure (low $\mathrm{H} / \mathrm{C}$ atomic ratio: 0.83 ). The DNAPL elemental composition allows us to calculate a theoretical molecular formula $\mathrm{C}_{53} \mathrm{H}_{43.5} \mathrm{O}_{2.5} \mathrm{~N}_{0.2} \mathrm{~S}$, used for the stoichiometric oxygen demand (SOD) determination. 


\section{Ferrate characterisation}

The Mössbauer analysis on ferrate (2) led to relative abundance (R.A) respectively (Online Resources Figure ESM_2a) of $42 \%$ attributed to the cations Fe VI, $27 \%$ for hematite, and $28 \%$ with goethite signature (Online Ressources Table ESM_2a). Crossed with iron content (200 g/kg) of ferrates (2), a purity of $29.8 \mathrm{wt} \%$ was calculated which differed from the supplier's data $(38.9 \mathrm{wt} \%)$, probably due to deactivation of the oxidant by contact with $\mathrm{CO}_{2}$ or moisture from the air during the transportation. Therefore, the oxidant dose calculated on the supplier's information was incorrect, and consequently, for all experiments with Ferrate (2), the oxidant stoichiometric amount was 0.77 SOD and not 1 SOD as for other oxidants.

\subsection{Oxidized samples}

\subsection{1 pH and iron mineral modifications}

Oxidations impacted the solution's pH (Table 2). It differed from a drastic acidification in the case of the persulfate ( $\mathrm{pH}$ dropped from neutral to 1 ), to rather basic conditions after use of permanganate $(\mathrm{pH} 9)$ or ferrates $(\mathrm{pH}>13)$. For both ferrates, $\mathrm{pH}$ rose, due to the impurity $(\mathrm{KOH})$ highly present in the ferrate powder, and due to the reaction. At these basic conditions, ferric sludge precipitated. Volume of dry residue, collected after freeze-drying step, was barely impacted by the oxidations, except for the ferrate (1) (less pure) whose precipitates doubled the final solid layer.

Mössbauer analysis carried out on the extraction residue from the sample oxidized by ferrate (2) showed no remaining $\mathrm{Fe}^{\mathrm{VI}}$ in the sample after seven days (Online Resources Figure ESM_2b and Table ESM_2b). It revealed as much sextet $\mathrm{Fe}^{3+}$ attributed to $\mathrm{Fe}(\mathrm{OH})_{3}$ as $\mathrm{Fe}^{\mathrm{VI}}$ initially present in the oxidant, attesting that ferrihydrite is the main by-product obtained from ferrate's oxidation under our conditions. Hematite and goethite phases, initially present, were not impacted by oxidation.

\subsubsection{Total Extractable Organic Matter EOM}

\section{Quantitative evolution}

To be representative of the oxidation efficiency, degradation rate and weight loss were calculated based on the blank tests (Fig2). DNAPL samples spiked and immediately following the extraction protocol $\left(\mathrm{t}_{0}\right)$ and blanks (at room temperature) carried out in contact with water over the reaction times, showed systematically $30.0 \mathrm{wt} \%$ EOM mass loss, due to protocol (evaporation). Heated blanks $\left(60^{\circ} \mathrm{C}\right)$ were losing higher EOM mass proportions: $56.2 \mathrm{wt} \%$. As a matter of fact, the degradation yields calculated in this study (for EOM and later PACs) correspond exclusively to oxidation but probably underestimate degradation efficiencies, as evaporated compounds lost in the blanks may have been previously oxidized during treatment, before the freeze drying and extraction procedures responsible for evaporation. The Fenton-like reaction resulted in $34.7 \mathrm{wt} \%$ EOM weight loss. The two tested ferrates were more effective: Ferrate (1) and (2) induced a weight loss of $65.8 \%$, and $44.4 \%$, respectively. 
With $82.6 \mathrm{wt} \%$ and $84.4 \mathrm{wt} \%$, permanganate and heat-activated persulfate resulted in the highest degradation.

\section{Qualitative evolution - Fourier Transformed Infra-red Spectroscopy (FTIR) analysis}

Like the initial DNAPL, FTIR spectra (Fig1) obtained after oxidation are dominated by aromatic bands $\left(\mathrm{vCH}_{\text {aro }}, \mathrm{vC}=\mathrm{C}\right.$ and $\left.\gamma \mathrm{CH}_{\text {aro }}\right)$, except in the case of persulfate oxidized sample where those bands have lower intensity.

After oxidation, only EOM from permanganate and the two ferrate treated samples showed an intense $\mathrm{vC}=\mathrm{O}$ band (1750-1700 $\mathrm{cm}^{-1}-$ Fig1 cde), suggesting an enrichment in oxygenated compounds. Neither activated persulfate nor Fenton-like oxidized sample exhibited this band.

\subsubsection{Quantified PAC evolution}

The PAC evolution is described by families: 16 PAHs, 2 furan O-PACs, 10 O-PAC ketones, 7 N-PACs and 4 S-PACs.

As for the EOM, the individual PAC degradation is calculated by comparison to the control sample (blanks). The concentration in those blanks, calculated in comparison to the $t_{0}$ samples, showed an average decrease in PAH, O-PAC, N-PAC and S-PAC concentrations of $-1.1 \%,-1.8 \% 17.2 \%$ and $1.5 \%$, respectively. At $60^{\circ} \mathrm{C}$, concentration decreases were higher with $46.3 \%$ for $\mathrm{PAH}, 46.4 \%$ for OPAC, $38.8 \%$ for N-PAC and $26.3 \%$ for S-PAC. Similarly, degradation yields are probably underestimated (especially at high temperature) by this blank-correction as oxidant may degrade part of compounds lost by evaporation due to extraction-protocol. PAH and polar-PAC (excepted O-PAC ketone) degradation

Whatever the oxidant, the degradations were intense in the beginning of the reaction (first 3 to 24 hours), before a slowing down (Fig3).

After one week, the highest PAC abatements were observed with heat activated persulfate and permanganate with a decrease of 96\% and 98\% in PAH (Fig3a), 98.5\% and 98.0\% in S-PAC (Fig3d) concentrations, respectively, and close to $100 \%$ in N-PAC content (Fig3c, concentrations below detection limit). In the case of the two furan O-PACs, the efficiency for the heat-activated persulfate is higher (95.7\%) than the permanganate (48.8\%). The Fenton-like reaction did not drastically decrease the PAC content (between $28.5 \%$ for PAHs, $17.4 \%$ for furan O-PACs, $63.7 \%$ for N-PACs and $31.2 \%$ for S-PACs). After seven days of reaction, PAH, furan O-PAC and N-PAC contents decreased of 77.9\%, $78.5 \%$ and $85.6 \%$ for ferrates $(1)$, and $57.0 \%, 63.0 \%$ and $68.7 \%$ for ferrates (2), respectively. In contrary, S-PAC decrease was more limited with $45.7 \%$ and $31.1 \%$ for ferrates (1) and (2), respectively.

\section{O-PAC ketone formation}


Most of the 10 targeted O-PAC ketones were detected in the initial DNAPL at low concentrations or close to the GC-MS detection limit (Table 1), except for the 9H fluorenone, slightly higher (2.3 $\left.\mathrm{mg} / \mathrm{g}_{\mathrm{DNAPL}}\right)$.

During oxidation, the abundance of O-PAC ketones increased in the case of permanganate and ferrates treatments and was still high after a week (Fig4). Their concentrations sharply rose in the beginning of the reaction $(3 \mathrm{~h})$ and was reduced only with permanganate oxidation after seven days. Discrepancies were observed between the two ferrates: ferrate (2) samples created lower amounts of O-PAC ketones than ferrate (1).

Results obtained with the Fenton-like reaction show a small increase in O-PAC ketone contents (from 42 to $99 \mu \mathrm{g} / \mathrm{g}$ after one week), whereas persulfate induced a decrease in those compound concentrations. Controls stayed constant, at $40 \mu \mathrm{g} / \mathrm{g}$ at $20^{\circ} \mathrm{C}$ and at $25 \mu \mathrm{g} / \mathrm{g}$ at $60^{\circ} \mathrm{C}$, (data not shown).

To investigate the production of other oxygenated by-products, a silylation was performed on the organic extracts before GC-MS analysis. No alcohols or acids were detected (data not shown).

\section{Discussion}

\subsection{Effect of the different oxidants on the pollutant content}

Except for the Fenton-like oxidation, main degradation of PACs is obtained in the three first hours, and may occur even sooner than our first measurement as other studies have already shown (Biache et al., 2015; Guan et al., 2014; Hanna et al., 2008; Peng et al., 2016).

As it could be seen with the DNAPL's composition, the PACs are standing for $16.2 \mathrm{wt} \%$ of the DNAPL. Whatever the oxidant, the EOM depletion was higher than those $16.2 \%$, implying that degradation affected the targeted PACs, but also other compounds in the DNAPL (Table 3).

However, PACs abatement most often showed better yields than EOM decrease, suggesting that the oxidants are selective to the PACs.

Fenton-like: The Fenton-like reaction showed lower efficiency in EOM and PAC degradation compared to the other oxidants: $34.7 \mathrm{wt} \%$ and $25.2 \%$, respectively. The conditions used in our experiments were not optimized as the hydrogen peroxide was poured drop by drop in one single addition (can undergo auto-decomposition if too concentrated), and the catalysis was probably disturbed.

Permanganate and persulfate: The best abatement efficiencies were obtained for heat activated persulfate (EOM decreased by $84.4 \mathrm{wt} \%$ and all PACs by $94.0 \%$ ) and permanganate (EOM $82.6 \mathrm{wt} \%$, PAHs $98.1 \%$ and all PACs $76.9 \%$ ). These two oxidants have shown highest efficiencies in other comparative studies (Boulangé et al., 2019a; Lemaire et al., 2019; Liao et al., 2019, 2018). The lower yield obtained on EOM depletion than on PAHs suggest a selectivity of these oxidants towards the 
targeted PACs, except for permanganate with the furans. Similar results were obtained by Biache et al (Biache et al., 2015) on LMW PAHs in a gas plant soil and a fresh PAH-contaminated wood-treatment facility soil with permanganate oxidation: PAHs seem preferentially degraded compared to the total EOM.

Ferrates: Due to the lower content of $\mathrm{Fe}^{\mathrm{VI}}$ in Ferrate (2) compared to the expected value (section 3.1 Ferrate characterization), the degradation rates obtained with Ferrate (1) are systematically higher than those of ferrate (2): $65.8 \%$ and $44.4 \%$ for EOM and $75.5 \%$ and $57.1 \%$ for total measured PACs, respectively. Consequently, estimated efficiencies based on 1 SOD have been recalculated in the case of ferrate (2) (Table 3), giving similar yields between the two ferrates.

Ferrates are very reactive and unstable in water, especially over $0.4 \mathrm{~g} / \mathrm{L}$ (supplier data). The more concentrated, the more unstable the solution is (Wagner et al., 1952). In this study, ferrates were used above this concentration. Loss of oxidant by undesired side-reactions may explain their lower efficiency compared to permanganate or persulfate. After seven days, PACs degradation was higher than the percentage of EOM depleted (Table 3) suggesting that ferrates degrade the bulk EOM but are selective towards the PACs. Similar results were obtained by Peings et al. (Peings et al., 2015) on wastewater effluent, where phenol was selectively oxidized despite the occurrence of other dissolved organic matter. Only the S-PACs seemed less affected by ferrate oxidation.

The application of one SOD oxidant turned out to be successful for permanganate and persulfate. Degradation rates were slightly lower for both ferrates, but that could be explained by their autodecomposition. The protocol was less optimized for the Fenton-like reaction. Other studies have highlighted formation of O-PACs during oxidation (Lampi et al. 2006; Lundstedt et al. 2007a; Russo et al. 2010; Biache et al. 2011; Guan et al. 2014; Peings et al. 2015; Ranc et al. 2017; Boulangé et al. 2019). That is why the monitoring of these oxygenated by-products is of importance.

\subsection{Formation of oxygenated by-products}

Because O-PACs (especially ketones) can be formed as reaction intermediates from incomplete PAH oxidation (Forsey et al., 2010; Lundstedt et al., 2007a), this study focused on ketone by-products.

With persulfate, no O-PAC ketones were generated, or were immediately degraded (Fig1f) and the ones occurring in the initial DNAPL were consumed. Ranc et al. (Ranc et al., 2017) observed the same tendency on a contaminated soil from the vadose zone: heat activated persulfate degraded the initial OPACs without generating new ones.

On the contrary, in case of permanganate and ferrate treatments, samples showed an enrichment in these oxygenated compounds (Fig4). 
The formation and the degradation of O-PAC ketones could be explained by the type of reactional mechanism occurring: (i) an oxido-reductive pathway with two electron-transfer like permanganate, which goes through a cyclic-ester formation before breaking into $\mathrm{C}-\mathrm{OH}$ or $\mathrm{C}=\mathrm{O}$ bonds (Petri et al., 2011a), (ii) the radical mechanism of activated persulfate and the Fenton-like reactions which attack the organic pollutant by hydrogen abstraction, hydroxyl addition or a single electron transfer (Bossmann et al., 1998). Mechanisms with two electron-transfer are going through formation of ketones or aldehydes, whereas radical reactions are not systematically. According to this observation, and knowing that the ferrates can follow oxido-reductive mechanism as well as a radical one (Sharma, 2013), the formation of oxygenated by-products (Fig4) suggests that ferrates highly react, under our conditions, according to an oxido-reductive pathway. Similarly, formation of O-PAC ketones with the Fenton-like oxidation suggests that the catalytic activation was incomplete, letting hydrogen peroxide reacts by an oxidoreductive pathway (Petri et al., 2011b). This could explain its lower efficiency.

In the case of permanganate treatment, when almost all PAHs have reacted, production of O-PAC ketone stops, and their degradation starts to be visible (after 24 hours), but reaction is not complete after seven days. However, permanganate is known to be persistent in soil for several weeks (Huling and Pivetz, 2006; Lemaire et al., 2013). With the oxidant dose of 1 SOD, batch reaction should continue further. Ranc et al. (Ranc et al., 2017) measured an oxidative activity of the permanganate even after 3 months, and also observed formation of numerous O-PAC ketones during oxidation of the contaminated coking plant soil (vadose zone, from the same site as our DNAPL), with a decrease in their concentrations after one month.

The O-PAC ketone formation obtained with ferrate (2) is about half the concentration obtained with ferrate (1). This difference is linked to the lower percentage of PACs degraded in the case of ferrate (2), this latter being used at a lower SOD dose. The formation of O-PACs is in accordance with the study of Guan et al. (Guan et al., 2014) who showed generation of ketones and aldehydes after ferrate oxidation of individual PAH (phenanthrene, pyrene and naphthalene). The main by-product they measured for phenanthrene degradation was the 9,10-phenanthraquinone, with $9 \mathrm{H}$-fluorenone also significantly observed. Unlike this study, the DNAPL oxidized in our experiments is a mixture of many PACs, and despite its complex composition, only high production of $9 \mathrm{H}$-fluorenone and, to a smaller extend, anthraquinone were observed. 


\subsection{Conclusion}

Batch oxidation of DNAPL were carried out in order to compare oxidants commonly used for soil treatment to ferrates (mainly studied for water treatments), in terms of PAC (PAH and polar PAC) degradation and oxygenated-PAC formation.

The Fenton-like reaction with magnetite addition was not successful on our samples probably due to problems with the catalytic activation (single $\mathrm{H}_{2} \mathrm{O}_{2}$ addition...).

Thanks to its radical activation, heat activated persulfate degraded almost all pollutants with no O-PAC ketone formation. Its main drawback is the massive decrease in $\mathrm{pH}$ and high increase in ionic strength (sulfate release). An alternative could be the use of an alkaline activation to limit $\mathrm{pH}$ decrease. However, ionic strength would still be increased in the water.

Permanganate was also very effective for DNAPL degradation. However, its oxido-reductive pathway and slower reactivity led to O-PAC ketone generation, and it released manganese salts $\left(\mathrm{MnO}_{2}\right.$ and $\mathrm{KMnO}_{4}$ ) which are known to have an impact on life redevelopment (Sirguey et al., 2008).

Ferrate's efficiency was attested for the degradation of a complex PAC mixture (DNAPL) from a polluted site, measured on sand, but it highly rose the $\mathrm{pH}$. Despite its use in high concentration (therefore unstable), it showed high degradation yields. The relatively high production of O-PAC ketones observed in our experiments suggests that oxidation followed an oxido-reductive pathway, similarly to the permanganate. Even if this potential O-PAC formation needs to be followed for field applications, this oxidant has the advantage of turning into nontoxic ferric sludge (which can adsorb and flocculate the remaining pollutants, data not observed in this study as water was freeze-dried).

The industrial production of ferrates is not currently fully developed, the ferrate powder is still very expensive today. Therefore, DNAPL degradation by ferrate on solids should be economically improved. Especially, some experiments with low concentrations of ferrate could be interesting to limit the selfdegradation of the oxidant. Moreover, thanks to the presence of ferric sludge and other iron species (hematite, goethite) in the ferrate powders we used, a combination of ferrates with hydrogen peroxide as Fenton-like reaction could be tested to investigate if a synergy exists between the two oxidants, as other studies seem to reveal (Lacina and Goold, 2015). Therefore, new batchs on DNAPL spiked sand are planned to explore those ideas. Additionally, some batchs will be conducted on DNAPL contaminated soil, instead of sand, to optimize the treatment and understand the impact of the soil's mineralogy and natural organic matter on oxidation reactions.

\section{Declaration of interest:}

Funding: This study was funded by the French Environmental Agency (ADEME) and the French National Association for Research and Technology (ANRT). The funding sources had no other involvement in this study. 
Conflict of interest: the authors declare that they are no conflict of interest.

Figure captions:

Fig1 Fourier Transformed Infra-Red spectra of the extracted organic matter of: a) the initial DNAPL, and after 1 week of oxidation by: b) Fenton-like, c) permanganate, d) ferrate (1), e) ferrate (2) and f) heat activated persulfate

Fig2 Mass loss of the Extractable Organic Matter (EOM) at different oxidation times (time in logarithmic scale) for each oxidant (Fenton-like, permanganate, ferrate (1) and (2) and heat activated persulfate)

Fig3 Degradation of targeted molecules obtained for permanganate, activated persulfate, Fenton-like and both ferrate oxidations at $3 \mathrm{~h}, 24 \mathrm{~h}$ and 7 days - time in logarithmic scale: a) 16 PAHs, b) 2 furanO-PACs, c) 7 N-PACs and d) 4 S-PACs

Fig4 Evolution of O-PAC ketone concentrations during the oxidation with permanganate, activated persulfate, Fenton-like and both ferrates $(\mathrm{K} 2 \mathrm{FeO} 4)$ - time in logarithmic scale

\section{References}

Bandowe, B.A.M., Wilcke, W., 2010. Analysis of Polycyclic Aromatic Hydrocarbons and Their Oxygen-Containing Derivatives and Metabolites in Soils. J. Environ. Qual. 39, 1349. doi:10.2134/jeq2009.0298

Bellamy, L.J., 1980. The Infrared Spectra of Complex Molecules. Springer Netherlands, Dordrecht. doi:10.1007/978-94-011-6520-4

Benhabib, K., Faure, P., Sardin, M., Simonnot, M.O., 2010. Characteristics of a solid coal tar sampled from a contaminated soil and of the organics transferred into water. Fuel 89, 352-359. doi:10.1016/j.fuel.2009.06.009

Biache, C., Ghislain, T., Faure, P., Mansuy-Huault, L., 2011. Low temperature oxidation of a coking plant soil organic matter and its major constituents: An experimental approach to simulate a long term evolution. J. Hazard. Mater. 188, 221-230. doi:10.1016/j.jhazmat.2011.01.102

Biache, C., Lorgeoux, C., Andriatsihoarana, S., Colombano, S., Faure, P., 2015. Effect of pre-heating on the chemical oxidation efficiency : Implications for the PAH availability measurement in contaminated soils. J. Hazard. Mater. 286, 55-63. doi:10.1016/j.jhazmat.2014.12.041

Bielski, B.H.J., Sharma, V.K., Czapski, G., 1994. Reactivity of ferrate(V) with carboxylic acids: A pre-mix pulse radiolysis study. Radiat. Phys. Chem. 44, 479-484. doi:10.1016/0969806X(94)90044-2

Birak, P.S., Miller, C.T., 2009. Dense non-aqueous phase liquids at former manufactured gas plants: Challenges to modeling and remediation. J. Contam. Hydrol. 105, 81-98. doi:10.1016/j.jconhyd.2008.12.001

Bossmann, S.H., Oliveros, E., Göb, S., Siegwart, S., Dahlen, E.P., Payawan, L., Straub, M., Wörner, M., Braun, A.M., 1998. New Evidence against Hydroxyl Radicals as Reactive Intermediates in 
the Thermal and Photochemically Enhanced Fenton Reactions. J. Phys. Chem. A 102, 55425550. doi:10.1021/jp980129j

Boulangé, M., Lorgeoux, C., Biache, C., Michel, J., Michels, R., Faure, P., 2019a. Aging as the main factor controlling PAH and polar-PAC (polycyclic aromatic compound) release mechanisms in historically coal-tar-contaminated soils. Environ. Sci. Pollut. Res. 26, 1693-1705. doi:10.1007/s11356-018-3708-1

Boulangé, M., Lorgeoux, C., Biache, C., Saada, A., Faure, P., 2019b. Fenton-like and potassium permanganate oxidations of PAH-contaminated soils: Impact of oxidant doses on PAH and polar PAC (polycyclic aromatic compound) behavior. Chemosphere 224, 437-444. doi:10.1016/j.chemosphere.2019.02.108

Cassidy, D.P., Srivastava, V.J., Dombrowski, F.J., Lingle, J.W., 2015. Combining in situ chemical oxidation, stabilization, and anaerobic bioremediation in a single application to reduce contaminant mass and leachability in soil. J. Hazard. Mater. 297, 347-355. doi:10.1016/j.jhazmat.2015.05.030

Castetbon, A., Costarramone, N., Boesinger, C., 2008. Procédé de préparation de ferrates de métaux alcalins. FR 2908128.

Chen, C.F., Binh, N.T., Chen, C.W., Dong, C. Di, 2015. Removal of polycyclic aromatic hydrocarbons from sediments using sodium persulfate activated by temperature and nanoscale zero-valent iron. J. Air Waste Manag. Assoc. 65, 375-383. doi:10.1080/10962247.2014.996266

Cheng, M., Zeng, G., Huang, D., Lai, C., Xu, P., Zhang, C., Liu, Y., 2016. Hydroxyl radicals based advanced oxidation processes (AOPs) for remediation of soils contaminated with organic compounds: A review. Chem. Eng. J. 284, 582-598. doi:10.1016/j.cej.2015.09.001

Clar, E., Schoental, R., 1964. Polycyclic hydrocarbons (Vol. 2), London: Ac. ed. London. doi:https://doi.org/10.1007/978-3-662-01668-8

de Souza e Silva, P.T., da Silva, V.L., Neto, B. de B., Simonnot, M.-O., 2009. Potassium permanganate oxidation of phenanthrene and pyrene in contaminated soils. J. Hazard. Mater. 168, 1269-1273. doi:10.1016/j.jhazmat.2009.03.007

Delle Site, A., 2001. Factors Affecting Sorption of Organic Compounds in Natural Sorbent/Water Systems and Sorption Coefficients for Selected Pollutants. A Review. J. Phys. Chem. Ref. Data 30, 187-439. doi:10.1063/1.1347984

Ferrarese, E., Andreottola, G., Oprea, I.A., 2008. Remediation of PAH-contaminated sediments by chemical oxidation. J. Hazard. Mater. 152, 128-139. doi:10.1016/j.jhazmat.2007.06.080

Filip, J., Yngard, R.A., Siskova, K., Marusak, Z., Ettler, V., Sajdl, P., Sharma, V.K., Zboril, R., 2011. Mechanisms and Efficiency of the Simultaneous Removal of Metals and Cyanides by Using Ferrate(VI): Crucial Roles of Nanocrystalline Iron(III) Oxyhydroxides and Metal Carbonates. Chem. - A Eur. J. 17, 10097-10105. doi:10.1002/chem.201100711

Forsey, S.P., Thomson, N.R., Barker, J.F., 2010. Oxidation kinetics of polycyclic aromatic 
hydrocarbons by permanganate. Chemosphere 79, 628-636.

doi:10.1016/j.chemosphere.2010.02.027

Gallard, H., de Laat, J., Legube, B., 1998. Effect of $\mathrm{pH}$ on the oxidation rate of organic compounds by Fe-II/H2O2. Mechanisms and simulation. New J. Chem. 22, 263-268. doi:10.1039/a708335a

Gan, W., Sharma, V.K., Zhang, X., Yang, L., Yang, X., 2015. Investigation of disinfection byproducts formation in ferrate(VI) pre-oxidation of NOM and its model compounds followed by chlorination. J. Hazard. Mater. 292, 197-204. doi:10.1016/j.jhazmat.2015.02.037

Gryzenia, J., Cassidy, D., Hampton, D., 2009. Production and accumulation of surfactants during the chemical oxidation of PAH in soil. Chemosphere 77, 540-545. doi:10.1016/j.chemosphere.2009.07.012

Guan, W., Xie, Z., Zhang, J., 2014. Preparation and Aromatic Hydrocarbon Removal Performance of Potassium Ferrate. J. Spectrosc. 2014, ID 171484, 8 pages. doi:10.1155/2014/171484

Hanna, K., Kone, T., Medjahdi, G., 2008. Synthesis of the mixed oxides of iron and quartz and their catalytic activities for the Fenton-like oxidation. Catal. Commun. 9, 955-959. doi:10.1016/j.catcom.2007.09.035

Hanser, O., Biache, C., Boulangé, M., Parant, S., Lorgeoux, C., Billet, D., Michels, R., Faure, P., 2014. Evolution of dissolved organic matter during abiotic oxidation of coal tar - comparison with contaminated soils under natural attenuation. Environ. Sci. Pollut. Res. 22, 1431-1443. doi:10.1007/s11356-014-3465-8

Hrabak, P., Homolkova, M., Waclawek, S., Cernik, M., 2016. Chemical degradation of PCDD/F in contaminated sediment. Ecol. Chem. Eng. S-CHEMIA I Inz. Ekol. S 23, 473-482. doi:10.1515/eces-2016-0034

Huang, K.C., Couttenye, R.A., Hoag, G.E., 2002. Kinetics of Heat-Assisted Persulfate Oxidation of Methyl tert -Butyl Ether (MTBE). Soil Sediment Contam. An Int. J. 11, 447-448. doi:10.1080/20025891107717

Huling, S.G., Pivetz, B.E., 2006. In-Situ Chemical Oxidation - Engineering Issue (No. ADA507297), Issue paper.

ITRC, 2005. Technical and Regulatory Guidance for In Situ Chemical Oxidation of Contaminated Soil and Groundwater, 2nd ed. Interstate Technol. Regul. Counc.

Jiang, J.Q., Panagoulopoulos, A., Bauer, M., Pearce, P., 2006. The application of potassium ferrate for sewage treatment. J. Environ. Manage. 79, 215-220. doi:10.1016/j.jenvman.2005.06.009

Johnson, M.D., Sharma, K.D., 1999. Kinetics and mechanism of the reduction of ferrate by oneelectron reductants. Inorganica Chim. Acta 293, 229-233. doi:10.1016/S0020-1693(99)00214-5

Jung, Y.S., Lim, W.T., Park, J., Kim, Y., 2009. Effect of pH on Fenton and Fenton-like oxidation. Environ. Technol. 30, 183-190. doi:10.1080/09593330802468848

Kakosová, E., Hrabák, P., Černík, M., Novotný, V., Czinnerová, M., Trögl, J., Popelka, J., Kuráň, P., Zoubková, L., Vrtoch, L., 2017. Effect of various chemical oxidation agents on soil microbial 
communities. Chem. Eng. J. 314, 257-265. doi:10.1016/j.cej.2016.12.065

Kwan, W.P., Voelker, B.M., 2002. Decomposition of Hydrogen Peroxide and Organic Compounds in The Presence of Iron and Iron Oxides. Environ. Sci. Technol. 36, 1467-1476.

Lacina, P., Goold, S., 2015. Use of the ferrates (FeIV-VI) in combination with hydrogen peroxide for rapid and effectIVe remediation of water - Laboratory and pilot study. Water Sci. Technol. 72, 1869-1878. doi:10.2166/wst.2015.414

Lampi, M.A., Gurska, J., McDonald, K.I.C., Xie, F., Huang, X.-D., Dixon, D.G., Greenberg, B.M., 2006. Photoinduced toxicity of Polycyclic aromatic hydrocarbons to Daphnia Magna:

Ultraviolet- mediated effects and the toxicity of polycyclic aromatic hydrocarbon photoproducts. Environ. Toxicol. Chem. 25, 1079. doi:10.1897/05-276R.1

Landais, P., Rochdi, A., 1990. Reliability of semiquantitative data extracted from transmission microscopy-Fourier transform infrared spectra of coal. Energy \& Fuels 4, 290-295. doi:10.1021/ef00021a013

Lee, S., Ören, A.H., Benson, C.H., Dovantzis, K., 2012. Organoclays as Variably Permeable Reactive Barrier Media to Manage NAPLs in Ground Water. J. Geotech. Geoenvironmental Eng. 138, 115-127. doi:10.1061/(ASCE)GT.1943-5606.0000572

Lemaire, J., Buès, M., Kabeche, T., Hanna, K., Lemaire, J., Buès, M., Kabeche, T., Hanna, K., Simonnot, M., 2013. Oxidant selection to treat an aged PAH contaminated soil by in situ chemical oxidation . J. Environ. Chem. Eng. 1, 1261-1268. doi:0.1016/j.jece.2013.09.018

Lemaire, J., Mora, V., Faure, P., Hanna, K., Buès, M., Simonnot, M.O., 2019. Chemical oxidation efficiency for aged, PAH-contaminated sites: An investigation of limiting factors. J. Environ. Chem. Eng. 7. doi:10.1016/j.jece.2019.103061

Liao, X., Wu, Z., Li, Y., Cao, H., Su, C., 2019. Effect of various chemical oxidation reagents on soil indigenous microbial diversity in remediation of soil contaminated by PAHs. Chemosphere 226, 483-491. doi:10.1016/j.chemosphere.2019.03.126

Liao, X., Wu, Z., Li, Y., Luo, J., Su, C., 2018. Enhanced degradation of polycyclic aromatic hydrocarbons by indigenous microbes combined with chemical oxidation. Chemosphere 213, 551-558. doi:10.1016/j.chemosphere.2018.09.092

Liu, H., Pan, X., Chen, J., Qi, Y., Qu, R., Wang, Z., 2019. Kinetics and mechanism of the oxidative degradation of parathion by Ferrate(VI). Chem. Eng. J. 365, 142-152. doi:10.1016/j.cej.2019.02.040

Lübcke-von Varel, U., Machala, M., Ciganek, M., Neca, J., Pencikova, K., Palkova, L., Vondracek, J., Löffler, I., Streck, G., Reifferscheid, G., Flückiger-Isler, S., Weiss, J.M., Lamoree, M., Brack, W., 2011. Polar Compounds Dominate in Vitro Effects of Sediment Extracts. Environ. Sci. Technol. 45, 2384-2390. doi:10.1021/es103381y

Lundstedt, S., White, P.A., Lemieux, C.L., Lynes, K.D., Lambert, I.B., Oberg, L., 2007a. Sources, Fate, and Toxic Hazards of Oxygenated Polycyclic Aromatic Hydrocarbons (PAHs) at PAH- 
contaminated Sites. Ambio 36, 475-485. doi:10.1579/0044-7447(2007)36

Lundstedt, S., White, P.A., Lemieux, C.L., Lynes, K.D., Lambert, I.B., Oberg, L., Haglund, P., Tysklind, M., 2007b. Sources, fate, and toxic hazards of oxygenated polycyclic aromatic hydrocarbons (PAHs) at PAH-contaminated sites. Ambio 36, 475-85.

Manoli, K., Morrison, L.M., Sumarah, M.W., Nakhla, G., Ray, A.K., Sharma, V.K., 2019.

Pharmaceuticals and pesticides in secondary effluent wastewater: Identification and enhanced removal by acid-activated ferrate(VI). Water Res. 148, 272-280. doi:10.1016/j.watres.2018.10.056

Marin-Morales, MA ; Leme, DM ; Mazzeo, D., 2009. A Review of the hazardous effects of polycyclic aromatic hydrocarbons on living organisms, in: Haines, PA; Hendrickson, M. (Ed.), POLYCYCLIC AROMATIC HYDROCARBONS: POLLUTION, HEALTH EFFECTS AND CHEMISTRY. Nova Science Publishers, pp. 1-49.

Mumtaz, M.M., George, J.D., 1995. Toxicological profile for polycyclic aromatic hydrocarbons, U.S. Department of Health and Human Services. doi:10.3109/15569529909037564

Munoz, M., de Pedro, Z.M., Casas, J.A., Rodriguez, J.J., 2015. Preparation of magnetite-based catalysts and their application in heterogeneous Fenton oxidation - A review. Appl. Catal. B Environ. 176-177, 249-265. doi:10.1016/j.apcatb.2015.04.003

Peings, V., Frayret, J., Pigot, T., 2015. Mechanism for the oxidation of phenol by sulfatoferrate(VI): Comparison with various oxidants. J. Environ. Manage. 157, 287-296. doi:10.1016/j.jenvman.2015.04.004

Peings, V., Pigot, T., Baylere, P., Sotiropoulos, J.-M., Frayret, J., 2017. Removal of pharmaceuticals by a potassium ferrate(VI) material: from practical implementation to reactivity prediction. Environ. Sci. Water Res. Technol. 3, 699-709. doi:10.1039/C7EW00038C

Peng, L., Wang, L., Hu, X., Wu, P., Wang, Xueqing, Huang, C., Wang, Xiangyang, Deng, D., 2016. Ultrasound assisted, thermally activated persulfate oxidation of coal tar DNAPLs. J. Hazard. Mater. 318, 497-506. doi:10.1016/j.jhazmat.2016.07.014

Pepino Minetti, R.C., Macaño, H.R., Britch, J., Allende, M.C., 2017. In situ chemical oxidation of BTEX and MTBE by ferrate: pH dependence and stability. J. Hazard. Mater. 324, 448-456. doi:10.1016/j.jhazmat.2016.11.010

Pera-Titus, M., García-Molina, V., Baños, M.A., Giménez, J., Esplugas, S., 2004. Degradation of chlorophenols by means of advanced oxidation processes: a general review. Appl. Catal. B Environ. 47, 219-256. doi:10.1016/j.apcatb.2003.09.010

Petri, B.G., Thomson, N.R., Urynowicz, M.A., 2011a. Fundamentals of ISCO using permanganate, in: Siegrist, R.L., Crimi, M., Simpkin, T.J. (Eds.), In Situ Chemical Oxidation for Groundwater Remediation. pp. 89-138. doi:10.1007/978-1-4419-7826-4

Petri, B.G., Watts, R.J., Teel, A.L., Huling, S.G., Brown, R.A., 2011b. Fundamentals of ISCO using Hydrogen Peroxide, in: Siegrist, R.L., Crimi, M., Simpkin, T.J. (Eds.), In Situ Chemical 
Oxidation for Groundwater Remediation. pp. 33-88. doi:10.1007/978-1-4419-7826-4

Rai, P.K., Lee, J., Kailasa, S.K., Kwon, E.E., Tsang, Y.F., Ok, Y.S., Kim, K.H., 2018. A critical review of ferrate(VI)-based remediation of soil and groundwater. Environ. Res. 160, 420-448. doi:10.1016/j.envres.2017.10.016

Ranc, B., Faure, P., Croze, V., Lorgeoux, C., Simonnot, M.O., 2017. Comparison of the effectiveness of soil heating prior or during in situ chemical oxidation (ISCO) of aged PAH-contaminated soils. Environ. Sci. Pollut. Res. 24, 11265-11278. doi:10.1007/s11356-017-8731-0

Ranc, B., Faure, P., Croze, V., Simonnot, M.O., 2016. Selection of oxidant doses for in situ chemical oxidation of soils contaminated by polycyclic aromatic hydrocarbons (PAHs): A review. J. Hazard. Mater. 312, 280-297. doi:10.1016/j.jhazmat.2016.03.068

Rivas, F.J., 2006. Polycyclic aromatic hydrocarbons sorbed on soils: A short review of chemical oxidation based treatments. J. Hazard. Mater. 138, 234-251. doi:10.1016/j.jhazmat.2006.07.048

Russo, L., Rizzo, L., Belgiorno, V., 2010. PAHs contaminated soils remediation by ozone oxidation. Desalin. Water Treat. 23, 161-172. doi:10.5004/dwt.2010.1990

Sharma, V.K., 2013. Ferrate(VI) and ferrate(V) oxidation of organic compounds: Kinetics and mechanism. Coord. Chem. Rev. 257, 495-510. doi:10.1016/j.ccr.2012.04.014

Sharma, V.K., 2008. Oxidative transformations of environmental pharmaceuticals by $\mathrm{Cl}$, $\mathrm{ClO} 2, \mathrm{O} 3$, and Fe(VI): Kinetics assessment. Chemosphere 73, 1379-1386. doi:10.1016/j.chemosphere.2008.08.033

Silva, P.T. de S. e, Silva, V.L. da, Neto, B. de B., Simonnot, M.-O., 2009. Phenanthrene and pyrene oxidation in contaminated soils using Fenton's reagent. J. Hazard. Mater. 161, 967-973. doi:10.1016/j.jhazmat.2008.04.042

Sirguey, C., Tereza de Souza e Silva, P., Schwartz, C., Simonnot, M.-O., 2008. Impact of chemical oxidation on soil quality. Chemosphere 72, 282-289. doi:10.1016/j.chemosphere.2008.01.027

Song, Y., Fang, G., Zhu, C., Zhu, F., Wu, S., Chen, N., Wu, T., Wang, Y., Gao, J., Zhou, D., 2019. Zero-valent iron activated persulfate remediation of polycyclic aromatic hydrocarboncontaminated soils: An in situ pilot-scale study. Chem. Eng. J. 355, 65-75. doi:10.1016/j.cej.2018.08.126

Tian, Z., Vila, J., Wang, H., Bodnar, W., Aitken, M.D., 2017. Diversity and Abundance of HighMolecular-Weight Azaarenes in PAH-Contaminated Environmental Samples. Environ. Sci. Technol. 51, 14047-14054. doi:10.1021/acs.est.7b03319

Trellu, C., Mousset, E., Pechaud, Y., Huguenot, D., van Hullebusch, E.D., Esposito, G., Oturan, M.A., 2016. Removal of hydrophobic organic pollutants from soil washing/flushing solutions: A critical review. J. Hazard. Mater. 306, 149-174. doi:10.1016/j.jhazmat.2015.12.008

Usman, M., Faure, P., Hanna, K., Abdelmoula, M., Ruby, C., 2012a. Application of magnetite catalyzed chemical oxidation (Fenton-like and persulfate) for the remediation of oil hydrocarbon contamination. Fuel 96, 270-276. doi:10.1016/j.fuel.2012.01.017 
Usman, M., Faure, P., Ruby, C., Hanna, K., 2012b. Remediation of PAH-contaminated soils by magnetite catalyzed Fenton-like oxidation. Appl. Catal. B Environ. 117-118, 10-17. doi:10.1016/j.apcatb.2012.01.007

Usman, M., Hanna, K., Haderlein, S., 2016. Fenton oxidation to remediate PAHs in contaminated soils: A critical review of major limitations and counter-strategies. Sci. Total Environ. 569, 179 190. doi:10.1016/j.scitotenv.2016.06.135

Venny, Gan, S., Kiat, H., 2012. Modified Fenton oxidation of polycyclic aromatic hydrocarbon ( PAH )-contaminated soils and the potential of bioremediation as post-treatment. Sci. Total Environ. 419, 240-249. doi:10.1016/j.scitotenv.2011.12.053

Voinov, M.A., Pagán, J.O.S., Morrison, E., Smirnova, T.I., Smirnov, A.I., 2011. Surface-mediated production of hydroxyl radicals as a mechanism of iron oxide nanoparticle biotoxicity. J. Am. Chem. Soc. 133, 35-41. doi:10.1021/ja104683w

Wagner, W., Gump, J., Hart, E., 1952. Factors Affecting Stability of Aqueous Potassium Ferrate (VI) Solutions. Anal. Chem. 24, 1497-1498. doi:10.1021/ac60069a037

Wang, C., Klamerth, N., Messele, S.A., Singh, A., Belosevic, M., El-Din, M.G., 2016. Comparison of $\mathrm{UV} /$ hydrogen peroxide, potassium ferrate(VI), and ozone in oxidizing the organic fraction of oil sands process-affected water (OSPW). Water Res. 100, 476-485. doi:10.1016/j.watres.2016.05.037

Wang, W., Liu, G., Shen, J., Chang, H., Li, R., Du, J., Yang, Z., Xu, Q., 2015. Reducing polycyclic aromatic hydrocarbons content in coal tar pitch by potassium permanganate oxidation and solvent extraction. J. Environ. Chem. Eng. Biochem. Pharmacol. 3, 1513-1521. doi:10.1016/j.jece.2015.05.024

Watts, R.J., Stanton, P.C., Howsawkeng, J., Teel, A.L., 2002. Mineralization of a sorbed polycyclic aromatic hydrocarbon in two soils using catalyzed hydrogen peroxide. Water Res. 36, 42834292. doi:10.1016/S0043-1354(02)00142-2

Wehrer, M., Rennert, T., Mansfeldt, T., Totsche, K.U., 2011. Contaminants at Former Manufactured Gas Plants: Sources, Properties, and Processes. Crit. Rev. Environ. Sci. Technol. 41, 1883-1969. doi:10.1080/10643389.2010.481597

Wenclawiak, B.W., Jensen, T.E., Richert, J.F.O., 1993. GC / MS-FID analysis of BSTFA derivatized polar components of diesel particulate matter ( NBS SRM-1650) extract* 808-812.

Yap, C.L., Gan, S., Ng, H.K., 2011. Fenton based remediation of polycyclic aromatic hydrocarbonscontaminated soils. Chemosphere 83, 1414-1430. doi:10.1016/j.chemosphere.2011.01.026

Yngard, R.A., Sharma, V.K., Filip, J., Zboril, R., 2008. Ferrate(VI) Oxidation of Weak-Acid Dissociable Cyanides. Environ. Sci. Technol. 42, 3005-3010. doi:10.1021/es0720816

Zamfirescu, D., Grathwohl, P., 2001. Occurrence and attenuation of specific organic compounds in the groundwater plume at a former gasworks site. J. Contam. Hydrol. 53, 407-427.

doi:10.1016/S0169-7722(01)00176-0 


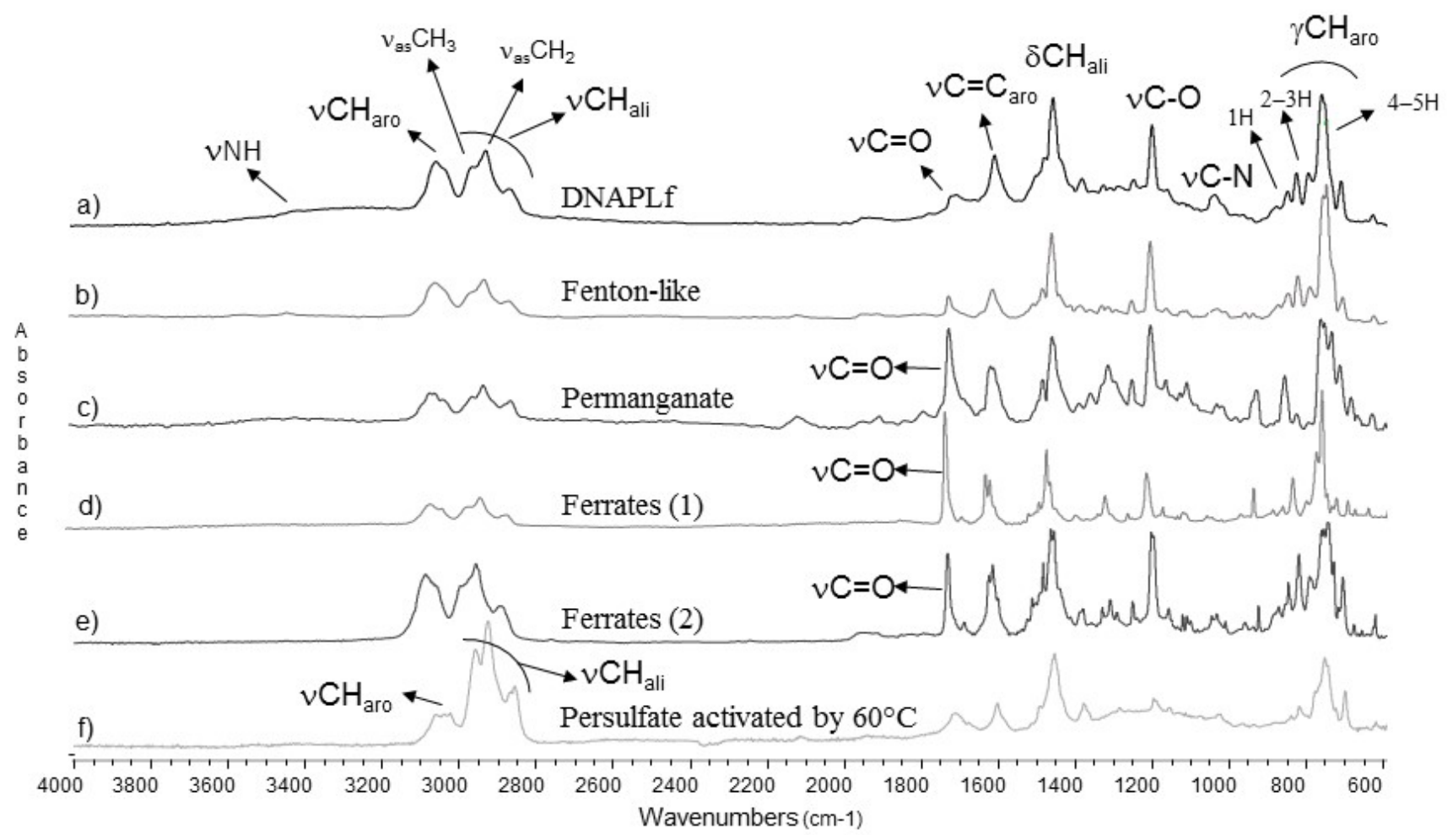

Fig1 


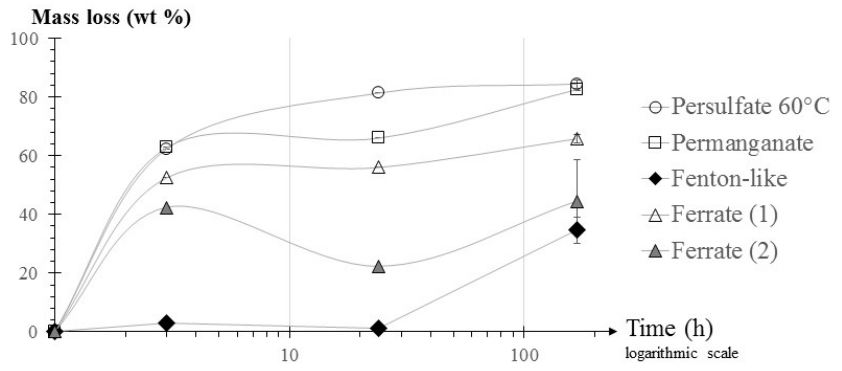

Fig2 
a) 16 US EPA PAHs

degradation (\%)

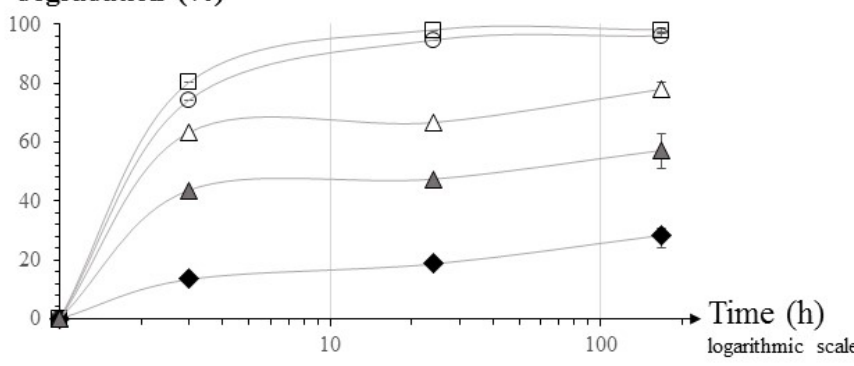

c) 7 N-PACs

degradation (\%)

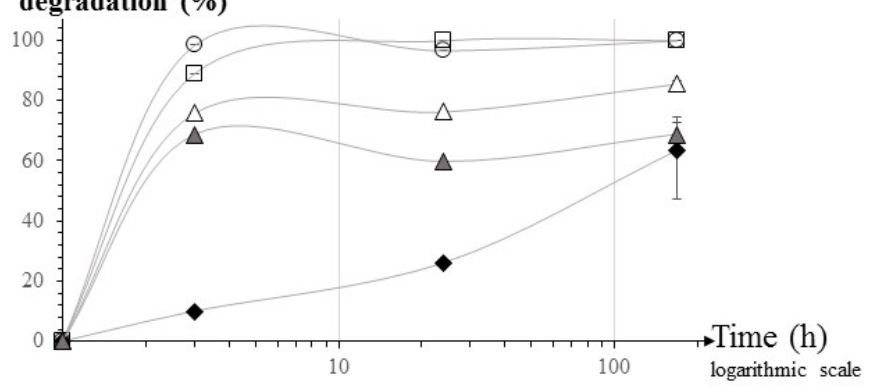

b) 12 O-PACs

degradation (\%)

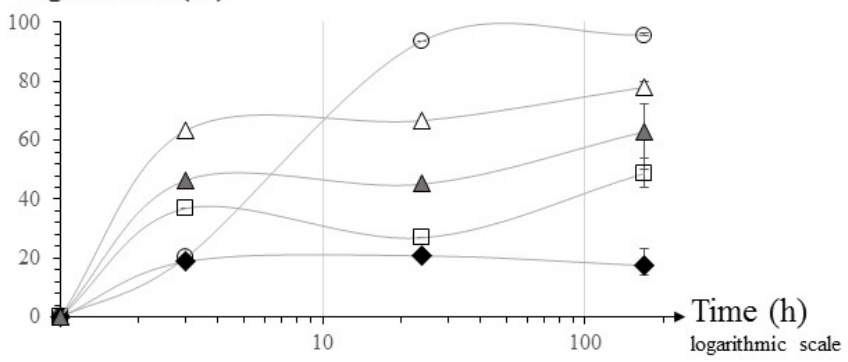

d) 4 S-PACs

degradation (\%)

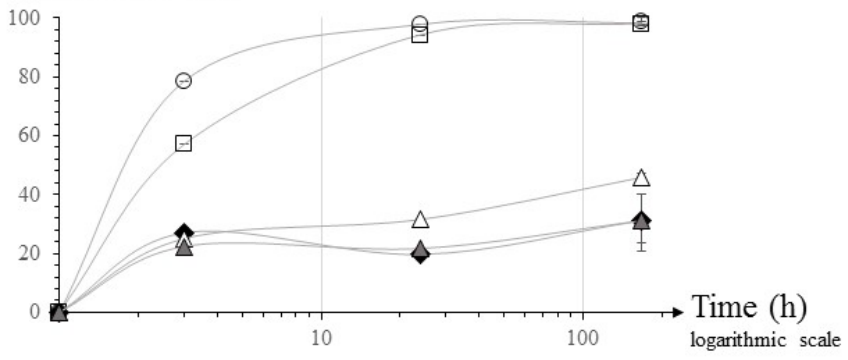

- Fenton-like $\triangle$ Ferrate (1) $\Delta$ Ferrate (2)

Fig3 


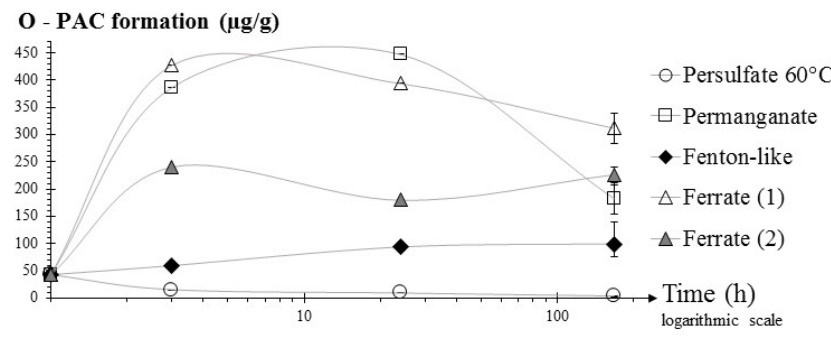

Fig4 
Table 1 - Composition of the DNAPL: 40 targeted PAH and polar-PAC concentrations in the DNAPL

Initial DNAPL

\begin{tabular}{|c|c|}
\hline \multicolumn{2}{|l|}{ PAHs (mg/kg) } \\
\hline Naphthalene & 127 \\
\hline Acenaphthylene & 2659 \\
\hline Acenaphthene & 26073 \\
\hline Fluorene & 25543 \\
\hline Phenanthrene & 27372 \\
\hline Anthracene & 5942 \\
\hline Fluoranthene & 4801 \\
\hline Pyrene & 2293 \\
\hline Benz[a]anthracene & 372 \\
\hline Chrysene & 197 \\
\hline Benzo[b]fluoranthene & 134 \\
\hline Benzo[k]fluoranthene & 99 \\
\hline Benz[a]pyrene & 165 \\
\hline Perylene & 77 \\
\hline Indeno $[1,2,3-c d]$ pyrene & 101 \\
\hline Dibenz[a,h]anthracene & $<$ \\
\hline Benzo[ghi]perylene & 62 \\
\hline$\Sigma 16$ PAHs (mg/kg) & 95900 \\
\hline \multicolumn{2}{|l|}{ S-PACs $(\mathrm{mg} / \mathrm{kg})$} \\
\hline Benzothiophene & 48 \\
\hline 2-methylbenzo[b]thiophene & 50 \\
\hline Dibenzothiophene & 4621 \\
\hline 4-methyldibenzothiophene & 266 \\
\hline$\Sigma 4$ S-PACs $(\mathrm{mg} / \mathrm{kg})$ & 4985 \\
\hline
\end{tabular}

Initial DNAPL

\begin{tabular}{|c|c|}
\hline O-PACs (mg/kg) & \\
\hline Dibenzofuran & 46666 \\
\hline 4-methyldibenzofuran & 6808 \\
\hline 9H-fluorenone & 2284 \\
\hline Perinaphtenone & 346 \\
\hline Anthraquinone & 679 \\
\hline Cyclopenta[def]phenanthrone & 88 \\
\hline Methylanthracene-9,10-dione & 324 \\
\hline Benz[a]fluorenone & 342 \\
\hline Benzanthrone & 47 \\
\hline Benzoanthracenedione & $<$ \\
\hline Naphtacene-5,12-dione & $<$ \\
\hline Benzo[cd]pyrenone & $<$ \\
\hline$\Sigma 12$ O-PACs (mg/kg) & 57584 \\
\hline$\Sigma 2$ O-PACs Furanes (mg/kg) & 53474 \\
\hline$\Sigma 10$ O-PACs ketones $(\mathrm{mg} / \mathrm{kg})$ & 4110 \\
\hline N-PACs (mg/kg) & \\
\hline Quinoline & 1001 \\
\hline Benzo[h]quinoline & 517 \\
\hline Acridine & $<$ \\
\hline Carbazole & 1335 \\
\hline Benzo[c]acridine & 124 \\
\hline Nitropyrene & 108 \\
\hline$\Sigma 5$ N-PACs (mg/kg) & 3085 \\
\hline
\end{tabular}


Table $2-\mathrm{pH}$ evolution of the water phase after seven days of reaction for each oxidant

\begin{tabular}{rc}
\hline \multicolumn{1}{c}{ Oxidant } & pH (after 7 days) \\
\hline Blank (water) & 7.9 \\
Fenton-like (magnetite) & 6.5 \\
Permanganate $\left(\mathrm{KMnO}_{4}\right)$ & 9.1 \\
Ferrate $1\left(\mathrm{~K}_{2} \mathrm{FeO}_{4}\right)$ & 13.9 \\
Ferrate $2\left(\mathrm{~K}_{2} \mathrm{FeO}_{4}\right)$ & 13.9 \\
Heat activated Persulfate $\left(\mathrm{Na}_{2} \mathrm{~S}_{2} \mathrm{O}_{8}\right)$ & 1.2 \\
\hline
\end{tabular}


Table 3 - Abatement (\%) of total organic extract mass (EOM) and PAC family concentrations after oxidations, calculated by comparison to the blanks after seven days of oxidation. (* recalculated for 1 SOD considering linear proportion)

\begin{tabular}{|c|c|c|c|c|c|c|}
\hline Abatement (\%) & $\begin{array}{l}\text { Fenton-like } \\
\text { (magnetite) }\end{array}$ & $\begin{array}{l}\text { Ferrate } 1 \\
\left(\mathrm{~K}_{2} \mathrm{FeO}_{4}\right)\end{array}$ & $\begin{array}{l}\text { Ferrate } 2 \\
\left(\mathrm{~K}_{2} \mathrm{FeO}_{4}\right)\end{array}$ & $\begin{array}{l}\text { Ferrate } 2 \\
\left(\mathrm{~K}_{2} \mathrm{FeO}_{4}\right)\end{array}$ & $\begin{array}{l}\text { Permanganate } \\
\left(\mathrm{KMnO}_{4}\right)\end{array}$ & $\begin{array}{l}\text { Heat activated } \\
\text { persulfate } \\
\left(\mathrm{Na}_{2} \mathrm{~S}_{2} \mathrm{O}_{8}\right)\end{array}$ \\
\hline & $1 \mathrm{SOD}$ & 1 SOD & 0.77 SOD & $\begin{array}{c}1 \text { SOD } \\
\text { (recalculated*) }\end{array}$ & 1 SOD & 1 SOD \\
\hline EOM & 34.7 & 65.8 & 44.4 & 57.7 & 82.6 & 84.4 \\
\hline$\Sigma 16 \mathrm{PAHs}$ & 28.5 & 77.9 & 57.0 & 74 & 98.1 & 96.1 \\
\hline$\Sigma 10$ O-PACs Furans & 17.4 & 78.5 & 63.0 & 81.8 & 48.8 & 95.7 \\
\hline$\Sigma 5 \mathrm{~N}-\mathrm{PACs}$ & 63.7 & 85.6 & 68.7 & 89.2 & 100 & 100 \\
\hline$\Sigma 4$ S-PACs & 81.2 & 45.7 & 31.1 & 40.4 & 98.0 & 98.5 \\
\hline $\begin{array}{r}\text { Total PACs (without } \\
\text { O-PAC ketones) }\end{array}$ & 25.2 & 75.5 & 57.1 & 74.2 & 76.9 & 94.0 \\
\hline
\end{tabular}

